\title{
The Influence of Sepiolite Orientation and Concentration, on the Morphological, Thermal and Mechanical Properties of Bio-Polyamide 4.10 Nanocomposites
}

\author{
María Asensio $\mathbb{D}^{1}{ }^{1}$ Manuel Herrero, ${ }^{2}$ Karina Núñez, ${ }^{2}$ Juan Carlos Merino, ${ }^{1,2}$ José María Pastor ${ }^{1,2}$ \\ ${ }^{1}$ Department of Condensed Matter Physics, Escuela de Ingenierías Industriales, University of Valladolid, Valladolid, \\ Spain \\ ${ }^{2}$ Foundation for Research and Development in Transport and Energy (CIDAUT), Parque Tecnológico de Boecillo, \\ Valladolid, Spain
}

\begin{abstract}
Nowadays, trends in automotive sector are toward highperformance materials, but also the concern about the environment has become an important driver for car manufacturers. In this sense, reinforced polymers are lightweight materials that can replace metals in some structural applications with an outstanding contribution to reduce the carbon dioxide emissions. In short fiber-reinforced polymers, processed by injection molding, the fibers are oriented in multiple and arbitrany directions. Due to the arrangement of the fibers, these materials present different thermomechanical behavior. In this study, bio-polyamide 4.10/sepiolite (0-15 wt $\%)$ nanocomposites obtained by melt compounding were injected using a square plate mold. Specimens were mechanized in different directions $\left(0^{\circ}, 45^{\circ}\right.$, and $\left.90^{\circ}\right)$ from this square plate and morphologically and thermomechanically tested. The sepiolite reinforcement results showed improvement in the thermomechanical properties. Moreover, despite the nanometer size of the reinforcement, the mechanical properties were also dependent on the fiber orientation during the injection molding of the nanocomposites. POLYM. ENG. SCI., 00:000-000, 2020. @ 2020 Society of Plastics Engineers
\end{abstract}

\section{INTRODUCTION}

Due to the increase of environmental awareness and drive toward environmentally sustainable technologies, materials derived from renewable sources have received significant interest in recent years. Bio-based materials could be an alternative to fossil-based materials, decreasing the dependence of petrol resources as well as to reduce carbon dioxide emissions [1]. Proof of the current interest in these materials is the growth rates, the global production capacity of bio-based materials is expected to increase from around 2.11 million tonnes in 2018 to 2.62 million tonnes in 2023 [2].

In this sense, bio-polyamides represent one of the most interesting alternatives to their fossil-based counterparts because of their good mechanical performance and high level of thermal and chemical resistance [3]. Bio-based polyamides have a mid to long chain length. These bio-based polyamides (PA610, PA1010, PA1012, and PA11) with straight chains allow superior performance in

Correspondence to: M. Asensio; e-mail: marase@cidaut.es

Contract grant sponsor: Consejería de Educación-Junta de Castilla y León; contract grant number: VA071G18. contract grant sponsor: Ministerio de Economía y Competitividad; contract grant number: MAT2017-85101-C2. DOI 10.1002/pen.25359

Published online in Wiley Online Library (wileyonlinelibrary.com).

(C) 2020 Society of Plastics Engineers terms of water absorption and, to some extent, chemical resistance than standard short chain polyamides (PA6, PA66). As bio-based polyamides are also shorter than their long-chain relatives (PA12), they outperform them in terms of mechanical strength and heat resistance. In general, polyamides can be divided into two large processing segments: $76 \%$ are processed by injection (car and truck parts, electrical and electronic parts, and so forth), $23 \%$ by extrusion (barrier films, wires and cables, pipes, and so forth), and $1 \%$ by others [4]. An example is the use of bio-PA in composites for automotive sector, where these materials are replacing steel and aluminum parts reducing the vehicle weight. Moreover, the future trends of the market toward the electric vehicle demand light materials with high mechanical and temperature performance [5-7].

In order to improve the performance of bio-polyamides and provide a competitive alternative to petroleum-based materials, bio-polyamides should be reinforced [8-10]. Nanoclays with layered structure are usually used to improve the thermomechanical properties of polyamide matrices, especially the montmorillonite [11-13]. Sepiolite with needle-like morphology is a natural fibrous mineral clay (microfibrillar morphology) with a theoretical unit cell formula $\mathrm{Mg}_{8} \mathrm{Si}_{12} \mathrm{O}_{30}(\mathrm{OH})_{4} \cdot\left(\mathrm{H}_{2} \mathrm{O}\right)_{4} \cdot 8 \mathrm{H}_{2} \mathrm{O}$ with an alternation of blocks and channels that grow up in the fiber direction [14]. Dimensions of sepiolite are between 0.2 and $4 \mu \mathrm{m}$ in length, 10 and $30 \mathrm{~nm}$ in width, and 5 and $10 \mathrm{~nm}$ in thickness [15]. As it has been reported, needle-like shape nanoclays, as sepiolite, can be dispersed within polymer matrix with less agglomeration, which leads to higher mechanical properties [16, 17].

Effects of clay reinforcement on different properties have been studied in different matrices by many researchers [18]. Ting-Cheng [19] studied the correlation of clay and the structure and thermal properties of the nanocomposites of a PA6. García-Lopez [20] reported impressive increase of elastic modulus and heat deflection temperature (HDT) with the reinforcement with sepiolite in PA6.

It is known that fiber orientation is related to the properties of reinforced bio-composites [21, 22]. In this sense, the orientation of different types of fiber has been studied over the properties of the material [23, 24]. Fiber orientation on tensile properties of two short glass fiber-reinforced polymer composites has been evaluated by Seyyedvahid Mortazavian et al. [25]. Andrea Bernasconi [26] investigated the influence of notch size and fiber orientation on the fatigue strength of a short glass fiber-reinforced PA6. Hartl et al. reported the effect of fiber orientation, stress state, and notch radius on the impact properties of short glass fiber-reinforced polypropylene [27]. Also, Lee et al. evaluated the thermomechanical anisotropy of talc and glass fiber-reinforced multiphase polymer composites [21]. The mentioned studies show the importance of extrapolating these concepts to bio-based matrices, polyamide 
4.10, and nanometric reinforcements, such as sepiolite, which despite its nanometric size leads to anisotropy due to its fiber morphology during injection.

In a previous work, we have detected an improvement in mechanical properties with the orientation of the nanofibers on PA6 [20]. The purpose of the present study is to analyze the effect of the sepiolite in a partially bio-based polyamide matrix. The effects of final content of sepiolite and its orientation during injection molding over the thermal properties, tensile tests, and service temperature have been studied.

\section{EXPERIMENTAL}

Materials

The partially bio-based polyamide applied in this work was the polyamide 4.10 (Bio-PA 4.10), produced by DSM (EcoPaXX150D). Bio-PA 4.10 offers zero $\mathrm{CO}_{2}$ emissions from its origin to its production, since the $\mathrm{CO}_{2}$ generated in the production is compensated by the $\mathrm{CO}_{2}$ absorbed during the growth of the plant. The nanoclay used in this research has been Sepiolite (Pangel S9) provided by Tolsa S.A. (Spain). Both, polyamide (Bio-PA4.10) and sepiolite were dried in an oven at $80^{\circ} \mathrm{C}$ for $24 \mathrm{~h}$ before the processing.

\section{Samples Preparation}

The compounding process was carried out in a co-rotating twin-screw extruder Leistriz $27 \mathrm{GL}$ (L/D = 36) with different amounts of sepiolite (5 and $15 \mathrm{wt} \%$ ). The investigation was carried out on 5 and $15 \mathrm{wt} \%$ of filler to study the properties and the orientation at a low concentration and a high concentration of filler. These selected quantities have been based on previous studies of PA 11 reinforced with sepiolite [3]. Temperature ramp were set from $240^{\circ} \mathrm{C}$ to $270^{\circ} \mathrm{C}$, from the feeding section to the material output section, respectively. The screw speed was set at $150 \mathrm{rpm}$ and the flow rate at $5 \mathrm{~kg} / \mathrm{h}$. Sepiolite was added using the lateral screw. The neat Bio-PA4.10 was manufactured using the same procedure to ensure the same thermal history.

Subsequently, a Krauss Maffei KM 200 injection molding machine was used to obtain the plate samples $\left(150 \times 150 \times 4 \mathrm{~mm}^{3}\right)$. The barrel temperature profiles were set from $260^{\circ} \mathrm{C}$ to $280^{\circ} \mathrm{C}$ and $80^{\circ} \mathrm{C}$ for the mold. In order to study the anisotropy of these plates, the specimens were obtained, by machining, in three different orientations respect the flow direction (Fig. 1).

Resultant bio-composites samples mechanized in different orientation will be referred through the paper as $\left(5 \% 0^{\circ}, 5 \% 45^{\circ}, 5 \%\right.$ $90^{\circ}$ ) for nanocomposites reinforced with $5 \mathrm{wt} \%$ of sepiolite and $\left(15 \% 0^{\circ}, 15 \% 45^{\circ}, 15 \% 90^{\circ}\right)$ for the nanocomposites with $15 \mathrm{wt} \%$ (Table 1).

It is well known that there are external areas on the injected plate where the fibers arrange randomly [28]. In order to prevent these effects, a distance about $40 \mathrm{~mm}$ from the injection molding location and $20 \mathrm{~mm}$ from the sides of the plate has been discarded (Fig. 1).

\section{Characterization}

Morphological Properties. Transmission electron microscopy (TEM). Sepiolite dispersion and orientation within BioPA4.10 was evaluated by TEM. Micrographs were taken through transmission electron microscope JEOL JEM-1011HPR working

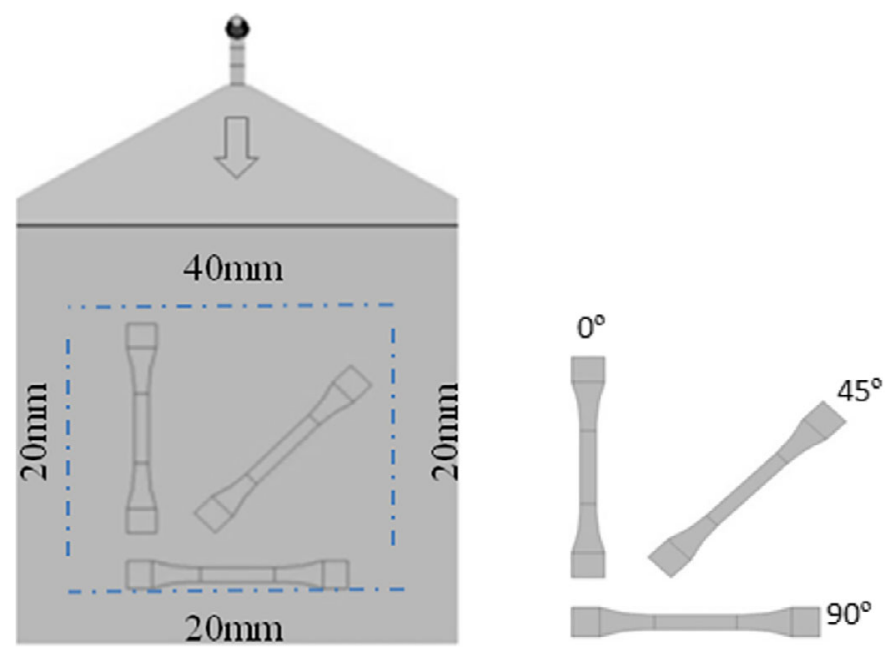

FIG. 1. Region and direction of specimens mechanized from injection molded plates. [Color figure can be viewed at wileyonlinelibrary.com]

TABLE 1. Nomenclature of nanocomposites.

\begin{tabular}{lcccc}
\hline & \multicolumn{3}{c}{ Orientation } \\
\cline { 2 - 4 } Samples & $0^{\circ}$ & $45^{\circ}$ & $90^{\circ}$ & \% clay \\
\hline PA4.10 & - & - & - & - \\
PA4.10/5\% & $5 \% 0^{\circ}$ & $5 \% 45^{\circ}$ & $5 \% 90^{\circ}$ & 5 \\
PA4.10/15\% & $15 \% 0^{\circ}$ & $15 \% 45^{\circ}$ & $15 \% 90^{\circ}$ & 15 \\
\hline
\end{tabular}

at $100 \mathrm{kV}$ of accelerating voltage. Samples $5 \% 0^{\circ}$ and $15 \% 0^{\circ}$ were fractured with RMC PowerTome ultramicrotome, using a MicroSTAR Diamond knife at room temperature.

Thermal Properties. Thermogravimetric analysis (TGA). TGA was used to determine the final sepiolite content in the nanocomposites. Thermograms were obtained in nitrogen atmosphere at a heating rate of $10^{\circ} \mathrm{C} / \mathrm{min}$ from $25^{\circ} \mathrm{C}$ to $900^{\circ} \mathrm{C}$ using a Mettler Toledo TGA851.

Differential scanning calorimetry (DSC). Melting and crystallization temperatures $\left(T_{\mathrm{m}}\right.$ and $\left.T_{\mathrm{c}}\right)$, and crystallinity $\left(X_{\mathrm{c}}\right)$ of the nanocomposites were measured by DSC, with Mettler Toledo DSC 851e. Temperature range was set from $25^{\circ} \mathrm{C}$ to $300^{\circ} \mathrm{C}$ and a heating rate of $20^{\circ} \mathrm{C} / \mathrm{min}$ under nitrogen flow. All samples were heating above their melting point, in order to remove the previous thermal history. Crystallinity degree was calculated using the heat of fusion for crystalline bio-polyamide 4.10 (269 J/g) [29].

Mechanical Properties. All specimens were maintained at a temperature of $23^{\circ} \mathrm{C} \pm 2{ }^{\circ} \mathrm{C}$ and a relative humidity of $50 \% \pm 10 \%$ before the mechanical tests.

Heat deflection temperature. CEAST HDT-3-VICAT P/N $6911 / 000$ was used to determine HDT. The heating rate was $2^{\circ} \mathrm{C} \pm 0.2^{\circ} \mathrm{C} / \mathrm{min}$ using $1.8 \mathrm{MPa}$ load, according to UNE-EN ISO 75. Three specimens of each sample were measured. 
Dynamic mechanical analysis (DMA). Mettler Toledo DMA 86/E dynamic mechanical analyzer was used to measured dynamic mechanical properties. The materials were measured in three-point bending mode at $1 \mathrm{~Hz}$ at a heating rate of $3^{\circ} \mathrm{C} / \mathrm{min}$ in the range of $-20^{\circ} \mathrm{C}$ to $100^{\circ} \mathrm{C}$. Three test specimens were evaluated. Samples were cut from injected plates $\left(50 \times 10 \times 4 \mathrm{~mm}^{3}\right)$.

Charpy impact. Ceast Resil Impactor 6957 impact pendulum was used to measure Charpy impact according to ISO 179. For each material, at least five test specimens were tested at room temperature.

Universal testing machine. The selected test specimens were type 1BA cut from the injected plates. Young's modulus and tensile strength were measured at different temperatures $\left(-40^{\circ} \mathrm{C}\right.$, $23^{\circ} \mathrm{C}$, and $85^{\circ} \mathrm{C}$ ) using a chamber TESTO Model $175-\mathrm{H} 2$ with an Instron Model 2620-601 at speed of 1 and $20 \mathrm{~mm} / \mathrm{min}$, respectively, according to ISO527-1. Five samples were used for each experiment.

\section{RESULTS AND DISCUSSION}

\section{Morphological Properties}

TEM micrographs of nanocomposites with $5 \%$ and $15 \%$ of sepiolite in the direction of the injection flow $\left(0^{\circ}\right)$ are given in Fig. 2. It can be observed when increasing the amount of sepiolite, there are more fibers oriented (Fig. 2b). On the other hand in Fig. 2a, the fibers are more dispersed. This can be explained considering a composite material as fibers suspended within a viscous medium. Therefore, in a fiber-filled material, three factors should be considered: the general fluid dynamics of the molten polymer, effects of the molten polymer on the fibers, and interfiber interactions. The influence of these depends on the concentration of nanocomposites, may be a dilute, medium, or concentrated. A dilute suspension is one in which the fibers are never close to one other and there are not interaction between them. A semiconcentrated suspension would have hydrodynamic interactions but not mechanical contact. In a concentrated suspension, the fiber orientation has both the behaviors, mechanical and hydrodynamic

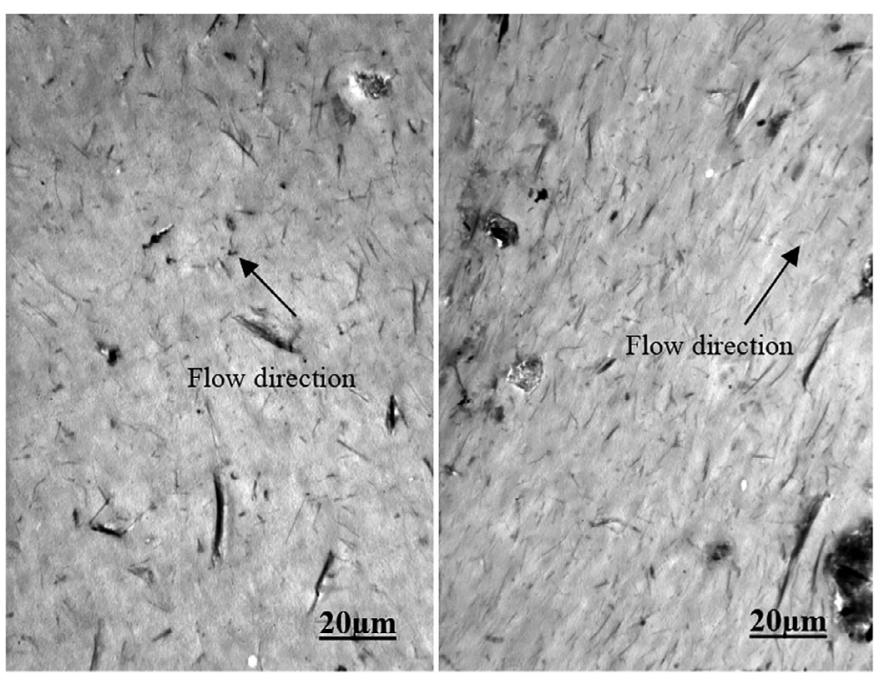

FIG. 2. TEM micrographs of (a) 5\% sepiolite and (b) $15 \%$ sepiolite. fiber interactions [30-33]. Looking at the pictures as a whole, $15 \%$ sepiolite can be regarded as a concentrate nanocomposite, presenting a strong orientation of the fibers. Otherwise, nanocomposites with $5 \%$ of sepiolite behaving like a semiconcentrated suspension. This preferred direction or not has repercussion in thermomechanical properties of nanocomposites.

\section{Thermal Properties}

Melting temperature $\left(T_{\mathrm{m}}\right)$, crystallization temperature $\left(T_{\mathrm{c}}\right)$, crystallinity degree $\left(X_{\mathrm{c}}\right)$ as well as the amount of clay incorporated from TGA are presented in Table 2. Crystallization and melting temperature presented almost the same values for the pure bio-polyamide and nanocomposites. Crystallization degree increases with the addition of sepiolite. This is due to sepiolite acted as nucleating agent increasing the crystallization degree $[3,34]$.

\section{Thermomechanical Properties}

Heat Deflection Temperature. Figure 3 shows HDT values of the neat bio-polyamide and its nanocomposites. The HDT value of neat polyamide is represented by dots while the values of the nanocomposites are showed by the bars. It can be observed that the HDT values increase with the rise of sepiolite content. The HDT for Bio-PA4.10 was approximately $80^{\circ} \mathrm{C}$, which achieved more than $130^{\circ} \mathrm{C}(63 \%)$ in nanocomposites with $5 \% 0^{\circ}$ and more than $155^{\circ} \mathrm{C}(96 \%)$ with $15 \% 0^{\circ}$. This increase can be explained due to the stiffening that promotes the reinforcement and to the nucleating effect of the nanoparticles [35].

On the other hand, as it can be observed in Fig. 3, in both cases, for same amount of clay added, the HDT for nanocomposites in $0^{\circ}$ were greater than those in $45^{\circ}$ and $90^{\circ}$. This important observation is due to the stiffness provided by the fibers in the flow injection direction $\left(0^{\circ}\right)$. This phenomenon is more noticeable with $15 \%$ of sepiolite. As the filler content increase, there were larger differences between the HDT values. At it is expected, the highest HDT value $\left(157^{\circ} \mathrm{C}\right)$ was observed for Bio-PA $4.10 / 15 \%$ with the fibers in the direction of the injection flow $\left(0^{\circ}\right)$. The results suggest that this bio-composite could be advantageous for applications where high service temperature is demanded.

Dynamic Mechanical Analysis. Results of storage modulus ( $\left.E^{\prime}\right)$ and damping parameter (Tan $\delta$ ) are showed in Fig. 4. Neat biopolyamide 4.10 and nanocomposites show the behavior of semicrystalline polymer (glassy, glass transition, and rubbery region).

Figure 4-1a,b shows how storage modulus increase with the addition of sepiolite. This stiffening effect produced by the filler is more noticeable with the increase of amount of sepiolite (15\%). Generally, this behavior is typical of sepiolite-based nanocomposites. Even

TABLE 2. Thermal properties of PA4.10 nanocomposites obtained with different amounts of sepiolite.

\begin{tabular}{lcccc}
\hline Sample & $T_{\mathrm{m}} \pm 0.5^{\circ} \mathrm{C}$ & $T_{\mathrm{c}} \pm 0.5^{\circ} \mathrm{C}$ & $X_{\mathrm{c}} \pm 1 \%$ & Sep (wt\%) \\
\hline PA4.10 & 251.1 & 224.9 & 32.1 & - \\
PA4.10/5\% & 250.0 & 224.2 & 35.3 & 4.87 \\
PA4.10/15\% & 249.1 & 224.5 & 35.7 & 12.49 \\
\hline
\end{tabular}



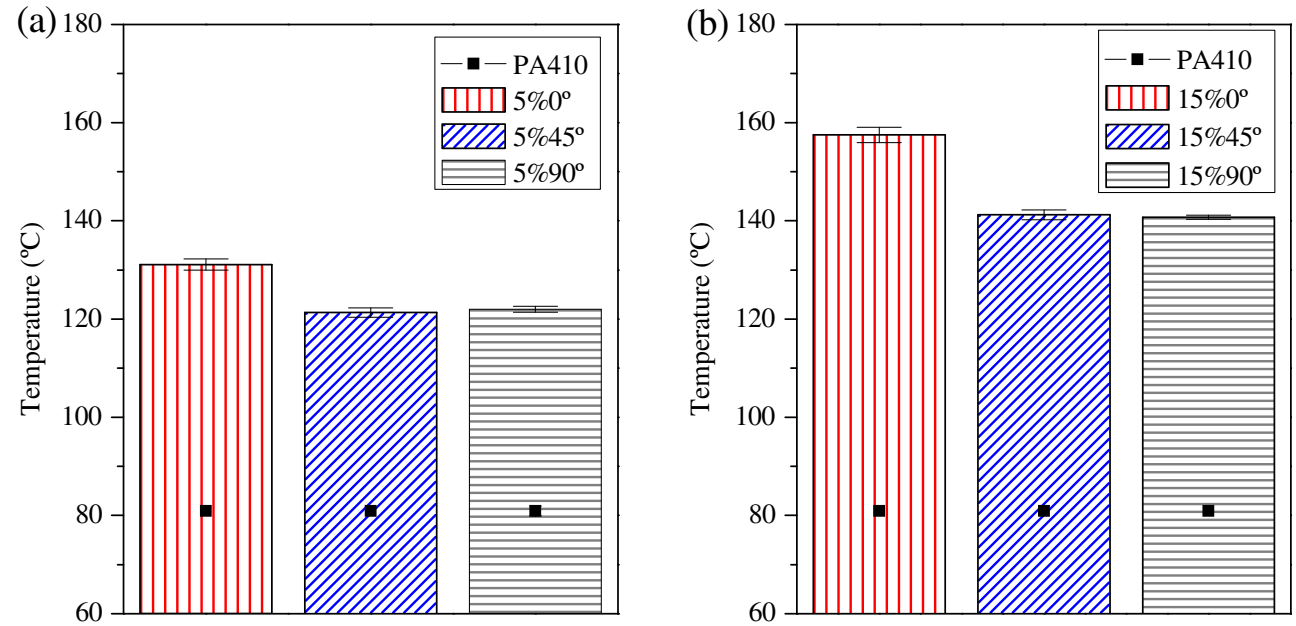

FIG. 3. Heat deflection temperature of bio-polyamide 4.10 and its nanocomposites: (a) bio-polyamide 4.10/5\%SEP and (b) bio-polyamide 4.10/15\%SEP. [Color figure can be viewed at wileyonlinelibrary.com]

(a)

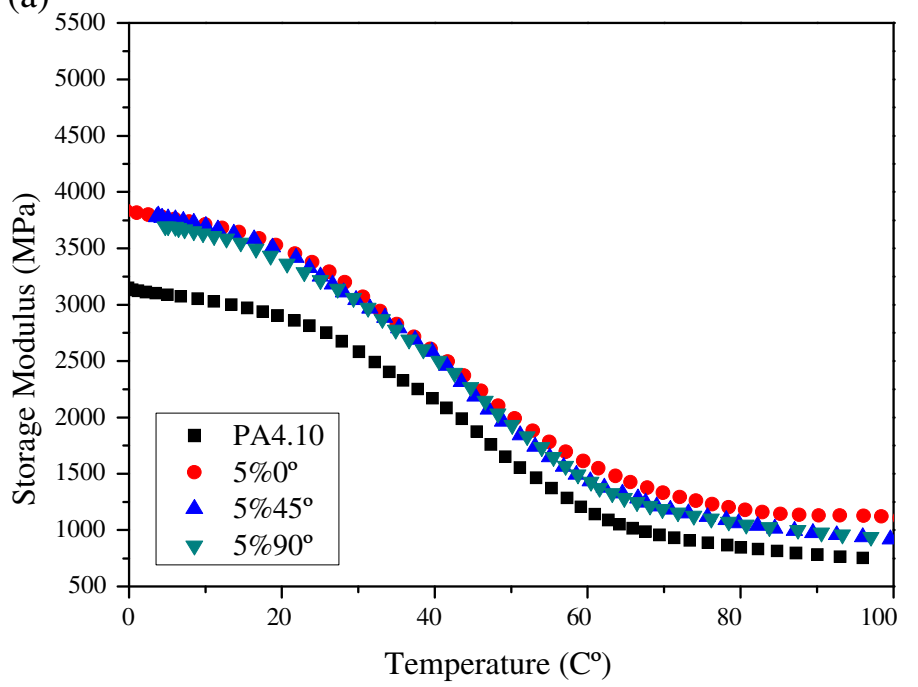

(c)

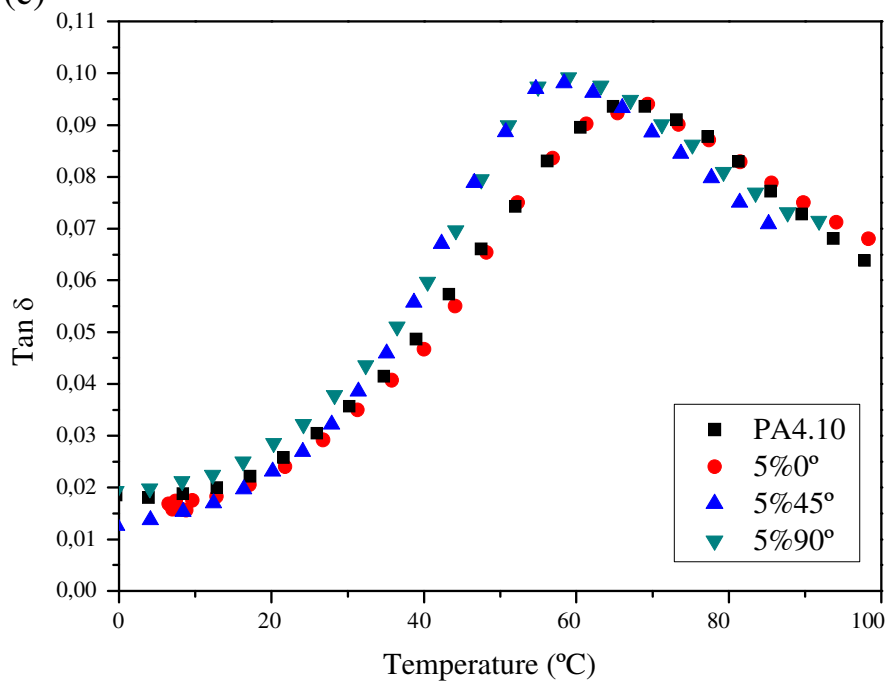

(b)

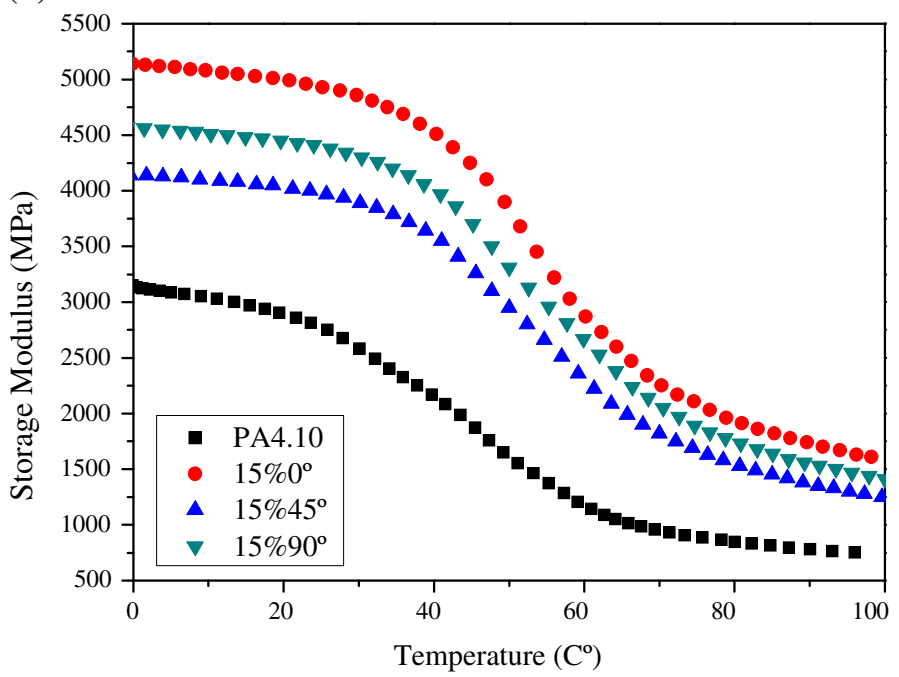

(d)

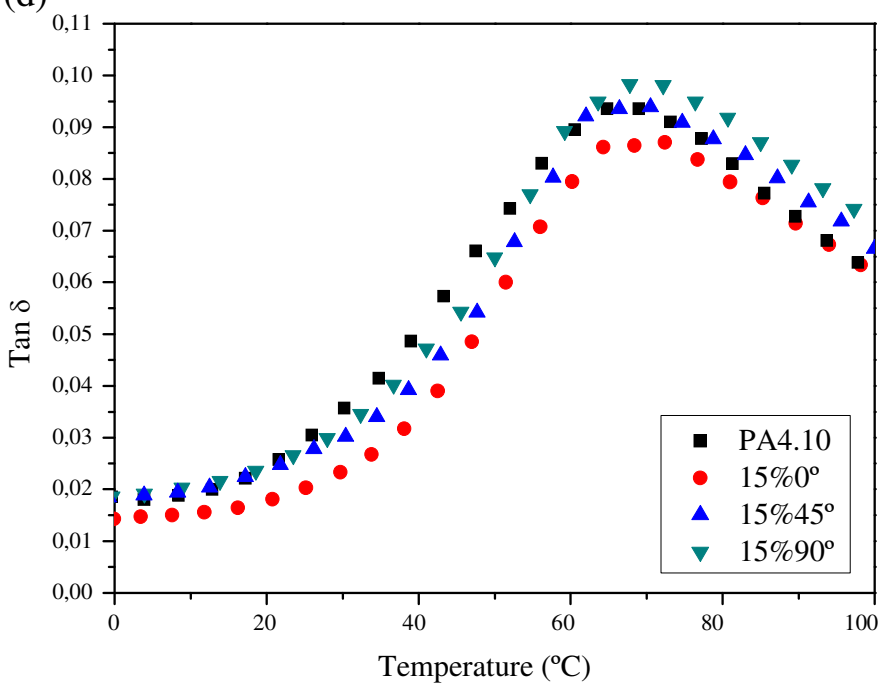

FIG. 4. Storage modulus (1) and damping parameter (Tan $\delta$ ) (2) for: (a) bio-polyamide $4.10 / 5 \%$ SEP and (b) biopolyamide $4.10 / 15 \%$ SEP. [Color figure can be viewed at wileyonlinelibrary.com] 

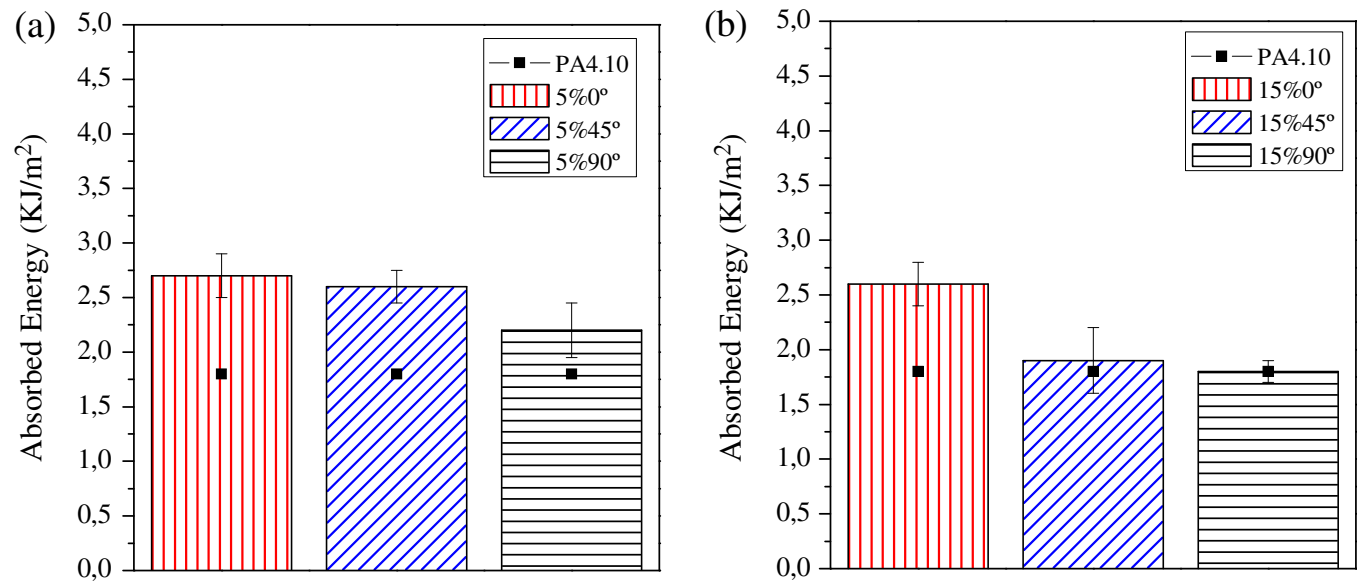

FIG. 5. Impact strength for pure bio-polyamide 4.10 and its composites with $5 \%$ clay content (a) and $15 \%$ clay content (b) in different fiber orientations. [Color figure can be viewed at wileyonlinelibrary.com]

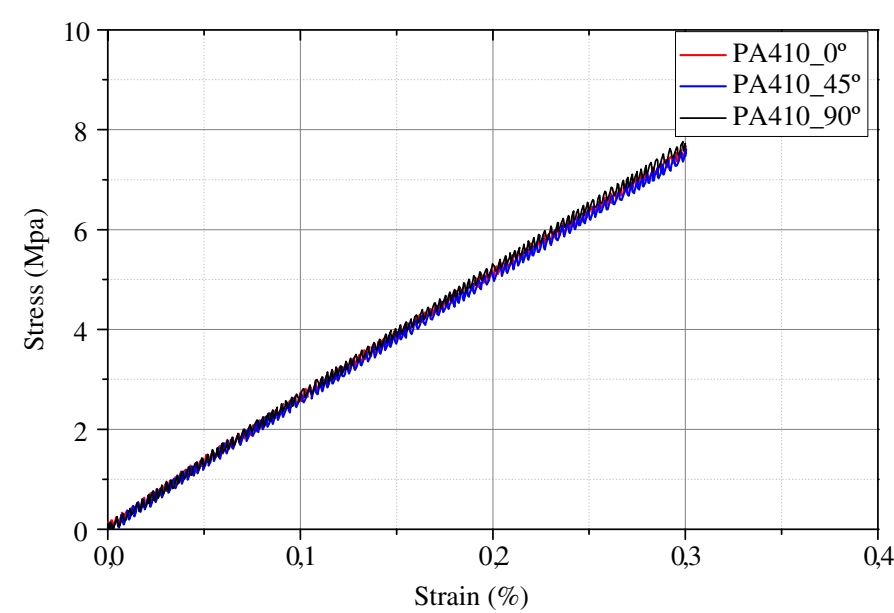

FIG. 6. Stress-strain curve of PA4.10 (non-reinforced) with different orientations $\left(0^{\circ}, 45^{\circ}, 90^{\circ}\right)$. [Color figure can be viewed at wileyonlinelibrary.com]

small amounts of fibers were sufficient to improve considerably the mechanical properties of these materials [36].

Concentration of sepiolite $(5 \%)$ at different directions $\left(0^{\circ}, 45^{\circ}\right.$, and $90^{\circ}$ ) showed similar storage modulus values (Fig. 4-1a). However, concentration of $15 \%$ of sepiolite showed differences between storage modulus values with the orientations (Fig. 4-1b). In the glassy state, the storage modulus in the direction of the fibers $\left(15 \% 0^{\circ}\right)$ was higher than those in $15 \% 90^{\circ}$ and $15 \% 45^{\circ}$. This is because in a more concentrated nanocomposite, the fiber orientation behavior becomes greater [37].

Tan $\delta$ graphs for nanocomposites with $5 \%$ and $15 \%$ of sepiolite are presented in Fig. 4-2a and 2b, respectively. Values of glass transition temperature $\left(T_{\mathrm{g}}\right)$ were taken from the maximum of Tan $\delta$ peak.

Tan $\delta$ peak temperature of nanocomposites with $5 \%$ of sepiolite at $45^{\circ}$ and $90^{\circ}$ shift $10^{\circ} \mathrm{C}$ with respect to the pure biopolyamide and the nanocomposite oriented at $0^{\circ}\left(69^{\circ} \mathrm{C}\right)$. This could be due to the fact that the fibers oriented at $90^{\circ}$ and $45^{\circ}$ cause the softening of the polymer chains reaching lower values in the Tan $\delta$ temperature (Fig. 4-2a). Nanocomposites with 15\% of sepiolite and pure PA (Fig. 4-2b) showed the Tan $\delta$ temperature around $69^{\circ} \mathrm{C}$ and the differences between samples were less than $1^{\circ} \mathrm{C}$. This proves that the glass transition temperatures of polymer matrix were not affected by the orientation of the sepiolite in the studied range.

It has been proved that when the amount of filler is increased, the Tan $\delta$ values decreases. This phenomenon is produced by the increase of restricted amorphous fraction in the polymeric matrix, associated with the rise of the amount of fiber [38]. However, as can be seen in graphs, Tan $\delta$ values are similar between concentrations and the different orientations. Only samples with $15 \% 0^{\circ}$ orientation present lower Tan $\delta$ values.

\section{Mechanical Properties}

Impact Properties. Impact strength for nanocomposites with 5\% and $15 \%$ of sepiolite at different fiber orientations are shown in Fig. 5. As discussed above, it is known that adding fibers to the polymeric matrix decreases the impact strength $[39,40]$. Referring to the orientation, especially $45^{\circ}$ and $90^{\circ}$ orientations presented lower values of energy absorption compared to $0^{\circ}$ orientation. This phenomenon may be because the nanofiber hinders the mobility of the polymer chain. In addition, the presence of the fiber in longitudinal position offers the Charpy hammer a greater resistance to the impact. This effect is more pronounced when the amount of clay is increased.

Mechanical Testing. Effect of matrix. Mechanical data of PA4.10 (non-reinforced) in different injection orientations were studied in order to dismiss the possible anisotropy in the molecular orientation of the polyamide when it is injected. Results showed that Young's modulus values of PA4.10 at $23^{\circ} \mathrm{C}$ were similar. Molecular orientation during injection molding does not produced differences between the orientations without load. Figure 6 shows stress-strain curve. In addition, the possible areas of greater orientation of the plates (outer areas) were cut and discarded for testing (Fig. 1).

Effect of nanocomposites. As it is known, mechanical properties of injection molded samples depend on the fiber orientation [41]. The tensile tests were carried out at three different temperatures $-40^{\circ} \mathrm{C}, 23^{\circ} \mathrm{C}$, and $80^{\circ} \mathrm{C}$ in order to check the mechanical 


\begin{tabular}{|c|c|c|c|c|c|}
\hline & & & Young's modulus & Tensile strength & Strain at break \\
\hline & Sample & $\%$ Sep & (Mpa) & (Mpa) & $(\%)$ \\
\hline$-40^{\circ} \mathrm{C}$ & PA4.10 & - & $3,740 \pm 102$ & $116 \pm 0.8$ & $7.7 \pm 1.0$ \\
\hline $23^{\circ} \mathrm{C}$ & PA4.10 & - & $2,390 \pm 77$ & $66.2 \pm 0.6$ & $6.1 \pm 1.0$ \\
\hline $85^{\circ} \mathrm{C}$ & PA4.10 & - & $976 \pm 25$ & $46.2 \pm 0.2$ & $100 \pm 2.1$ \\
\hline$-40^{\circ} \mathrm{C}$ & $5 \% 0^{\circ}$ & 5 & $4,526 \pm 100$ & $120.8 \pm 1.3$ & $4.47 \pm 0.33$ \\
\hline & $5 \% 45^{\circ}$ & 5 & $4,300 \pm 91$ & $119.9 \pm 0.9$ & $5.24 \pm 0.54$ \\
\hline & $5 \% 90^{\circ}$ & 5 & $4,400 \pm 50$ & $115.5 \pm 1.2$ & $5.20 \pm 0.07$ \\
\hline & $15 \% 0^{\circ}$ & 15 & $5,610 \pm 42$ & $85.6 \pm 1.4$ & $1.81 \pm 0.07$ \\
\hline & $15 \% 45^{\circ}$ & 15 & $5,246 \pm 28$ & $94.1 \pm 1.2$ & $2.18 \pm 0.18$ \\
\hline & $15 \% 90^{\circ}$ & 15 & $5,046 \pm 80$ & $99.7 \pm 1.0$ & $2.49 \pm 0.22$ \\
\hline $23^{\circ} \mathrm{C}$ & $5 \% 0^{\circ}$ & 5 & $3,080 \pm 30$ & $69.0 \pm 0.9$ & $32.55 \pm 0.32$ \\
\hline & $5 \% 45^{\circ}$ & 5 & $2,776 \pm 37$ & $63.9 \pm 1.0$ & $37.54 \pm 0.43$ \\
\hline & $5 \% 90^{\circ}$ & 5 & $2,736 \pm 100$ & $64.5 \pm 1.2$ & $36.63 \pm 0.56$ \\
\hline & $15 \% 0^{\circ}$ & 15 & $3,730 \pm 86$ & $67.2 \pm 0.8$ & $6.87 \pm 0.12$ \\
\hline & $15 \% 45^{\circ}$ & 15 & $3,390 \pm 35$ & $65.2 \pm 1.1$ & $7.69 \pm 0.34$ \\
\hline & $15 \% 90^{\circ}$ & 15 & $3,340 \pm 15$ & $64.9 \pm 1.0$ & $7.44 \pm 0.40$ \\
\hline $85^{\circ} \mathrm{C}$ & $5 \% 0^{\circ}$ & 5 & $1,210 \pm 59$ & $46.9 \pm 1.0$ & $34.37 \pm 0.25$ \\
\hline & $5 \% 45^{\circ}$ & 5 & $1,106 \pm 30$ & $42.1 \pm 0.9$ & $42.77 \pm 0.50$ \\
\hline & $5 \% 90^{\circ}$ & 5 & $1,110 \pm 36$ & $42.5 \pm 0.5$ & $38.77 \pm 0.43$ \\
\hline & $15 \% 0^{\circ}$ & 15 & $1,690 \pm 41$ & $43.2 \pm 0.6$ & $10.15 \pm 0.41$ \\
\hline & $15 \% 45^{\circ}$ & 15 & $1,455 \pm 70$ & $43.2 \pm 0.8$ & $13.84 \pm 0.52$ \\
\hline & $15 \% 90^{\circ}$ & 15 & $1,410 \pm 76$ & $42.8 \pm 0.4$ & $13.40 \pm 0.61$ \\
\hline
\end{tabular}
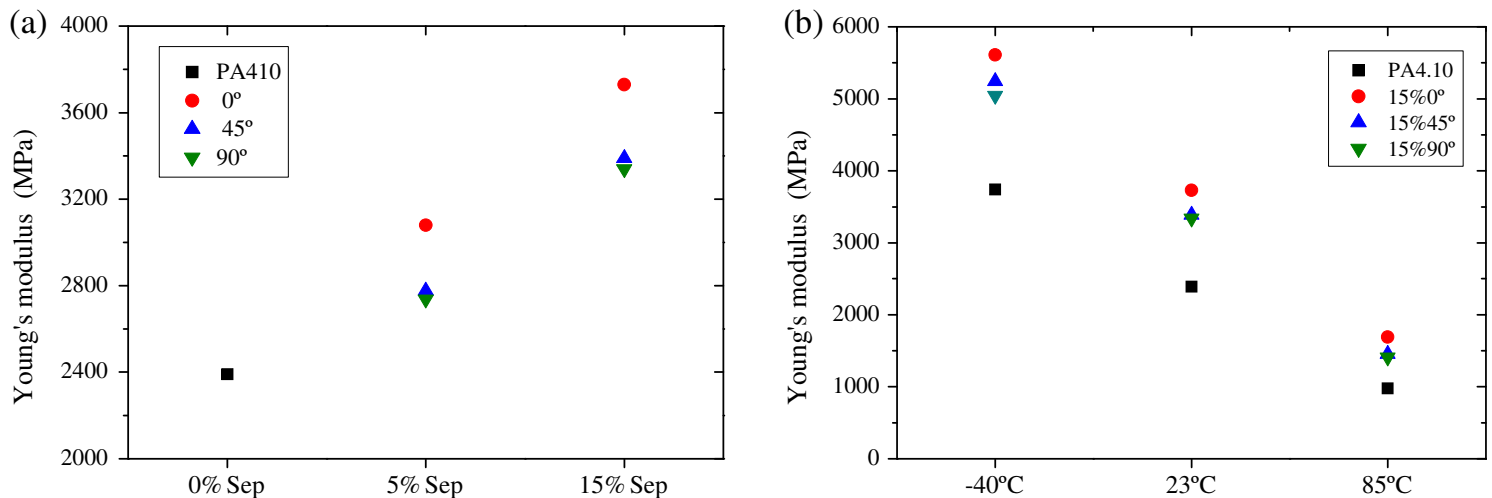

FIG. 7. Variation of Young's modulus with (a) amount of filler $(0 \%, 5 \%$, and $15 \%)$ and (b) temperature with $15 \%$.

[Color figure can be viewed at wileyonlinelibrary.com]

behavior at different operation conditions. Young's modulus, tensile strength and strain at break values of Bio-PA, and its nanocomposites are showed in Table 3.

Figure 7a shows the variation of Young's modulus with the amount of filler, while the relationship with the temperature is showed in Fig. 7b. As it has been reported, the incorporation of sepiolite increases the Young's modulus values [15] (Fig. 6a).

Another important observation is that mechanical properties depended on the direction of the measurement. It is well known that the mechanical properties of anisotropic materials are directional. It should be noted that the Young's modulus is always higher in bio-polyamides with fiber in the flow direction $\left(0^{\circ}\right)$ due to the stiffness provided by the fiber in longitudinal direction to the test.

The effects of orientation on Young's modulus for both concentrations are significant and the effect increases with decreasing temperature (Fig. 7b).
In addition, results revealed that with higher amount of filler, the Young's modulus increased and, at the same time, decreased the elongation at break values. It is well known that nanoclay enhanced the stiffness and reduces the elongation at break of the polymers [35].

Tensile properties of nanocomposites at different temperatures are shown in Fig. 8. It can be observed how the samples follow the same trend at different temperatures. The specimens at $0^{\circ}$ showed higher tensile strength, but less elongation at break. The specimens tested at $0^{\circ}$ are the ones that support the highest load; this is due to the stiffness provided by the fiber. As well as at $0^{\circ}$ orientation, the fibers withstand the pressure, when fiber is oriented in $45^{\circ}$ and $90^{\circ}$, the sepiolite supports less load. This behavior is reflected in the increase of elongation at break, obtaining more ductile materials at $45^{\circ}$ and $90^{\circ}$ orientations. This is because the influence of the matrix affects more than the fiber. 

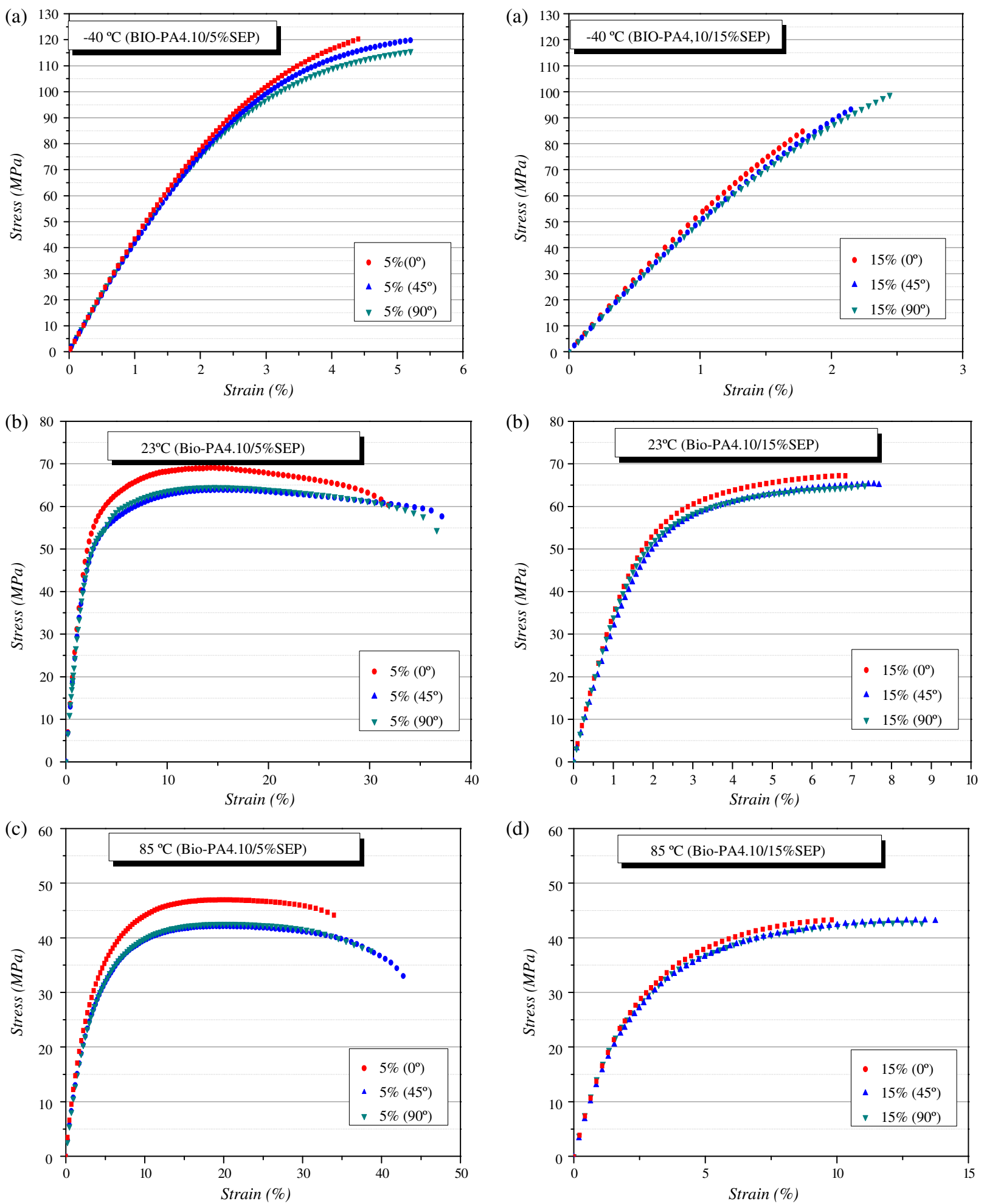

FIG. 8. Tensile curves of nanocomposites: left side (5\% sepiolite content) and right side (15\% sepiolite content), at (a) $-40^{\circ} \mathrm{C}$, (b) $23^{\circ} \mathrm{C}$, and (c) $85^{\circ} \mathrm{C}$. [Color figure can be viewed at wileyonlinelibrary.com]

\section{CONCLUSION}

Bio-based polyamide nanocomposites, with 5 and $15 \mathrm{wt} \%$ sepiolite contents, were prepared using melt compounding technique. The first conclusion to be draw is the use of sepiolite as an effective reinforcement for the bio-polyamide 4.10.
It has been proven that this increases the thermomechanical properties.

In this work, the microstructural anisotropy of sepiolitereinforced bio-polyamide composites was studied. These reinforcements, despite their nanometric size, showed an orientation 
during the injection molding flow; as a consequence, the anisotropy was reflected in the final properties.

The nanocomposites of Bio-PA have allowed obtaining a material from renewable resources with high requirements for its use in current vehicles and in the future trends, that is, toward the electric vehicle. Higher modulus and tensile strength were achieved with the orientation, as well as higher operating temperature. In this way, the use of nanoclays has been optimized, achieving with its orientation the important increase in the final properties.

\section{ACKNOWLEDGMENTS}

Authors wish express the gratitude to "Ministerio de Economía y Competitividad" (Spain) for the financial support project MAT2017-85101-C2. Moreover, to the Consejería de Educación-Junta de Castilla y León (project VA071G18 and grant to M.A.).

\section{REFERENCES}

1. J. Pagacz, K.N. Raftopoulos, A. Leszczyńska, and K. Pielichowski, J. Therm. Anal. Calorim., 123(2), 1225 (2016). https://doi.org/10.1007/s10973-015-4929-x.

2. S. Wright, Pap Eur., 11(10), 24 (2000). https://doi.org/10.1136/ bmj.1.5165.62.

3. M. Herrero, M. Asensio, K. Núñez, J.C. Merino, and J.M. Pastor, Polym. Compos., 40, E704 (2019). https://doi.org/10.1002/pc. 24962.

4. B. Brehmer, Bio-Based Plast. Mater. Appl., 275 (2014). https:// doi.org/10.1002/9781118676646.ch10.

5. S.A. Pradeep, R.K. Iyer, H. Kazan, and S. Pilla, Automotive Applications of Plastics: Past, Present, and Future. 2nd ed., Elsevier Inc., Clemson University (2016). https://doi.org/10.1016/ B978-0-323-39040-8.00031-6.

6. O. Akampumuza, P.M. Wambua, A. Ahmed, W. Li, and X. H. Qin, Polym. Compos., 38(11), 2553 (2017). https://doi.org/10. 1002/pc.23847.

7. A.K. Mohanty, M. Misra, and L.T. Drzal, J. Polym. Environ., 10 (1-2), 19 (2002). https://doi.org/10.1023/A:1021013921916.

8. D. Battegazzore, O. Salvetti, A. Frache, N. Peduto, A. De Sio, and F. Marino, Compos. Part A Appl. Sci. Manuf., 81, 193 (2016). https://doi.org/10.1016/j.compositesa.2015.11.022.

9. K. Liu, S.A. Madbouly, J.A. Schrader, M.R. Kessler, D. Grewell, and W.R. Graves, J. Appl. Polym. Sci., 132(48) (2015). https:// doi.org/10.1002/app.42592.

10. Z. Liu, P. Zhou, and D. Yan, J. Appl. Polym. Sci., 91(3), 1834 (2004). https://doi.org/10.1002/app.13336.

11. S. Yu, J. Zhao, G. Chen, Y.K. Juay, and M.S. Yong, J. Mater. Process. Technol., 192-193, 410 (2007). https://doi.org/10.1016/ j.jmatprotec.2007.04.006.

12. R. Gallego, D. García-López, J.C. Merino, and J.M. Pastor, Polym. Int., 59(4), 472 (2010). https://doi.org/10.1002/pi.2724.

13. H. Qin, Q. Su, S. Zhang, B. Zhao, and M. Yang, Polymer (Guildf), 44(24), 7533 (2003). https://doi.org/10.1016/j.polymer. 2003.09.014.

14. K. Núñez, R. Gallego, J.M. Pastor, and J.C. Merino, Appl. Clay Sci., 101, 73 (2014). https://doi.org/10.1016/j.clay.2014.07.020.

15. E. Bilotti, H.R. Fischer, and T. Peijs, J. Appl. Polym. Sci., 107 (2), 1116 (2008). https://doi.org/10.1002/app.25395.
16. J.B. Olivato, J. Marini, F. Yamashita, E. Pollet, M.V. E. Grossmann, and L. Avérous, Mater. Sci. Eng. C, 70(Part 2), 296 (2017). https://doi.org/10.1016/j.msec.2016.08.077.

17. E. Ruiz-Hitzky, M. Darder, F.M. Fernandes, B. Wicklein, A.C. S. Alcântara, and P. Aranda, Prog. Polym. Sci., 38(10-11), 1392 (2013). https://doi.org/10.1016/j.progpolymsci.2013.05.004.

18. Y. Zhou, F. Pervin, V.K. Rangari, and S. Jeelani, J. Mater. Process. Technol., 191(1-3), 347 (2007). https://doi.org/10.1016/j. jmatprotec.2007.03.059.

19. T.C. Li, J. Ma, M. Wang, W.C. Tjiu, T. Liu, and W. Huang, J. Appl. Polym. Sci., 103(2), 1191 (2007). https://doi.org/10. 1002/app.25378.

20. D. García-López, J.F. Fernández, J.C. Merino, J. Santarén, and J. M. Pastor, Compos. Sci. Technol., 70(10), 1429 (2010). https:// doi.org/10.1016/j.compscitech.2010.05.020.

21. D.J. Lee and Y.S. Song, Compos. Struct., 174, 329 (2017). https://doi.org/10.1016/j.compstruct.2017.04.065.

22. Y. Fan, Y.C. Lu, Y. Lu, et al., Polym. Plast. Technol. Eng., 52 (10), 964 (2013). https://doi.org/10.1080/03602559.2013.763369.

23. T.B. Nguyen Thi, M. Morioka, A. Yokoyama, S. Hamanaka, K. Yamashita, and C. Nonomura, J. Mater. Process. Technol., 219, 1 (2015). https://doi.org/10.1016/j.jmatprotec.2014.11.048.

24. D. O'Regan and M. Akay, J. Mater. Process. Technol., 56(1-4), 282 (1996). https://doi.org/10.1016/0924-0136(95)01842-5.

25. S. Mortazavian and A. Fatemi, Compos. Part B Eng., 72, 116 (2015). https://doi.org/10.1016/j.compositesb.2014.11.041.

26. A. Bernasconi, E. Conrado, and P. Hine, Polym. Test., 47, 12 (2015). https://doi.org/10.1016/j.polymertesting.2015.08.002.

27. A.M. Hartl, M. Jerabek, and R.W. Lang, Polym. Test., 43, 1 (2015). https://doi.org/10.1016/j.polymertesting.2015.01.020.

28. M.B.D. Akay, J. Mater. Sci., 26, 2731 (1991).

29. C.S. Moran, A. Barthelon, A. Pearsall, V. Mittal, and J. R. Dorgan, J. Appl. Polym. Sci., 133(45), 1 (2016). https://doi. org/10.1002/app.43626.

30. J.L. Oliver, P. Bernaola-Galván, M. Hackenberg, and P. Carpena, BMC Evol. Biol., 8(1) (2008). https://doi.org/10.1186/1471-21488-107.

31. F. Folgar and C.L. Tucker, J. Reinf. Plast. Compos., 3(2), 98 (1984). https://doi.org/10.1177/073168448400300201.

32. S.M. Dinh and R.C. Armstrong, J. Rheol. (N Y N Y), 28(3), 207 (1984). https://doi.org/10.1122/1.549748.

33. J.G. Tropsch, Int. News Fats, Oils Relat. Mater., 28(6), 20 (2017). https://doi.org/10.16953/deusbed.74839.

34. Z. Wu, C. Zhou, and N. Zhu, Polym. Test., 21(4), 479 (2002). https://doi.org/10.1016/S0142-9418(01)00113-1.

35. M. Asensio, M. Herrero, K. Núñez, R. Gallego, J.C. Merino, and J.M. Pastor, Eur. Polym. J., 100, 278 (2018). https://doi.org/10. 1016/j.eurpolymj.2018.01.034.

36. M.T. Takemori, Polym. Eng. Sci., 19(15), 1104 (1979). https:// doi.org/10.1002/pen.760191507.

37. J.L. Thomason, Compos. Part A Appl. Sci. Manuf., 40(2), 114 (2009). https://doi.org/10.1016/j.compositesa.2008.10.013.

38. A. Kiziltas, D.J. Gardner, Y. Han, and H.S. Yang, Thermochim. Acta, 519(1-2), 38 (2011). https://doi.org/10.1016/j.tca.2011. 02.026 .

39. J.L. Thomason and M.A. Vlug, Compos. Part A Appl. Sci. Manuf., 28(3), 277 (1997). https://doi.org/10.1016/S1359-835X (96)00127-3. 
40. S. Yu, W.M. Yek, S.Y. Ho, S.A.D. Rannou, and S.H. Lim, Mater. Today Commun., 4, 199 (2015). https://doi.org/10.1016/j. mtcomm.2015.08.004.
41. S.-Y. Fu, X. Hu, and C.-Y. Yue, J. Soc. Mater. Sci. Japan, 48(6 Appendix), 74 (1999). https://doi.org/10.2472/jsms.48.6Appen dix_74. 